\title{
Fatal Elephant Encounters on Humans in Bangladesh: Context and Incidences
}

\author{
A.H.M. Raihan Sarker ${ }^{1}$, Amir Hossen $^{2} \&$ Eivin Røskaft ${ }^{2}$ \\ ${ }^{1}$ Institute of Forestry and Environmental Sciences, University of Chittagong, Chittagong 4331, Bangladesh \\ ${ }^{2}$ Department of Biology, Norwegian University of Science and Technology, NTNU, Realfagbygget 7491 \\ Trondheim, Norway \\ Correspondence: Eivin Røskaft, Department of Biology, Norwegian University of Science and Technology, \\ NTNU, Realfagbygget 7491 Trondheim, Norway. Tel: 47-9065-2883. E-mail: roskaft@bio.ntnu.no
}

Received: March 27, 2015 Accepted: April 10, 2015 Online Published: April 12, 2015

doi:10.5539/enrr.v5n2p99 URL: http://dx.doi.org/10.5539/enrr.v5n2p99

\begin{abstract}
Here we report the context encounters of elephant attacks on humans in Bangladesh, during the period 1989 to 2012. Attack rates significantly increased over this study period. The proportion of encounters that caused deaths or injuries differed statistically significant between the two sexes (men more deaths), age groups (elder more deaths), time of the day (more deaths during night), place of casualty (more deaths outside forests), weapon used by elephants (more deaths when elephants were using both trunk and leg) and study sites. No difference was found between seasons, elephant group size, or financial status, occupation and household size of victims. Elephant family groups were mostly responsible for attacks in the north, while single bulls were more responsible in the southeast. The place of casualty (inside or outside forests), time of the day, gender and regions were all significant in explaining the variation in encounters which resulted in human deaths or injuries. Conflict mitigation approaches including incentive-, awareness-or training programs from the forest department could help to reduce the conflict between humans and elephants in Bangladesh.
\end{abstract}

Keywords: human-elephant conflict, human injuries and deaths, Bangladesh

\section{Introduction}

Humans are considered to be users of ecosystem services as forests and natural resources and conflict intensity between humans and wildlife is dependent on the level of resource utilisation, access and control priority (Hossain, 2008; Jones \& Carswell, 2004; Robbins, 2012). The potential cost of living near a protected area is particularly high when the concerned animals are large and dangerous, such as the Asian (Elephas maximus) and African elephants (Loxodonta africana). One of the calamities of the interaction between elephants and people is that elephants kill people even without any direct provocation (Røskaft, Larsen, Mojaphoko, Sarker \& Jackson, 2014).

In Bangladesh, the Asian elephant population is restricted to the south-eastern and northern forest areas. In addition, a trans-border movement of elephants into Bangladesh from Meghalaya and Assam in India and Myanmar has been observed. According to Sarker and Røskaft (2011), the size of the wild elephant population in Bangladesh varies between 150 and 200 animals. Wild elephants in Bangladesh can thus be divided into two categories, (i) a local migratory- and (ii) a trans-border migratory population. Local migratory elephants frequently visit different habitat patches in their home range at specific time intervals.

Wild elephants which have been considered protected in Bangladesh, often venture into villages, mostly at night, to look for food, thereby frequently damaging crops and attack villagers. In 2014 (December 17), three people were killed and another one was injured as raiding elephants invaded several villages at Satkania upazila of Chittagong district in south-eastern Bangladesh (PA, 2014). In November 2001, a herd of some 15 elephants stormed the villages at Rangunia in Chittagong district. They pulled down a number of bamboo and straw houses, damaged crops and killed four people in addition to damaging 15 villagers (Reuters, 2001). A middle-aged man was killed by an elephant attack at Kamarkhali village in Durgapur upazila of the Netrokona district, which is located near the political border between Bangladesh and India (New-Nation, 2015). Three victims died when herds of elephants stormed two farming villages near a forest at Ukhia, Cox's Bazar (Personal communication with Matiur Rahman, ex-deputy commissioner of Cox's Bazar district). Elephants destroyed nearly 15 straw and 
bamboo-made houses, leaving some 100 people homeless (Reuters, 2002). In India, during the years 1980-2000, about 150-200 people lost their lives yearly due to attacks by wild elephants --- a total of 3,000 to 4,000 people over these two decades (Sukumar, 2004). Information from Sri Lanka indicates that 30-50 people are killed annually (Bandara \& Tisdell, 2002). Similar figures are found in Kenya during the past decades caused by African elephants (Sukumar, 2004).

In Bangladesh, elephants have gradually been confined to 'pocketed herds' in small patches of forests, which in most cases are surrounded by human settlements. Such 'pocketed herds' represent an extreme stage of human-elephant conflict in the south-eastern and northern regions of Bangladesh and make the wild elephants almost a seasonal invader into farm fields and dwelling places resulting in many human fatalities (Sarker \& Røskaft, 2010).

Manslaughter by elephants is common during two kinds of contexts: (i) under "normal" circumstances in the wilderness or in settlements within a large, natural elephant habitat and (ii) under "abnormal" circumstances, such as when a large herd or clan of mostly crop-raiding elephants disperse to a new habitat (Sukumar, 2004). Human deaths in the forest are usually chance encounters when people are walking alone or in small groups from one settlement to another, visiting a small shrine on a hill top, grazing livestock, collecting firewood and other forest products, or even when humans are sleeping under the shade of a tree (Ramakrishnan \& Ramkumar, 2007). While most incidents have been taking place during daytime, it is noteworthy that several of these incidents occurred at dark / dusk very close to human settlements where bull elephants were waiting for the cover of darkness to enter cultivated land (Sukumar, 2004). For example, forest dependant resource collectors and farmers are mostly at risk of wild elephant attacks when they are working inside or near the forest (Sarker \& Røskaft, 2010). Victims have mostly been men guarding crop fields at night from simple structures at ground level, although on occasion's women or children have been attacked when a riding bull broke down a hut (Ramakrishnan \& Ramkumar, 2007).

Elephant biology also attributes to its periodical aggressive behaviour leading to conflict and human fatalities (Sukumar, 1989). Attacks resulting in fatalities in the forest are frequently due to solitary bulls but occasionally also by members of family groups (Sukumar, 2004). The elephants are often killed together with the human victim (Sarker \& Røskaft, 2010). In contrast, practically all human killings within cultivated land are caused by sub-adult or adult bulls (Sarker \& Røskaft, 2011). A flashlight shined at a bull or the sound of a dog barking often evokes an aggressive reaction (Sukumar, 1989). Farmers sometimes use dogs to warn them of the presence of raiding elephants. If an elephant chase the dog, the latter would naturally tend to run back to its master, bringing behind it an elephant which might redirect its aggression to the person (Sukumar, 1989). Another common pattern seen is that a few notorious bulls may be responsible for multiple killings. Both in the forest and within fields, elephants kill people by lashing out with the trunk, grasping and flinging, trampling or goring with the tusks. There have been occasional incidents involving photographers approaching elephants and even a curious foreigner possibly unaware of the danger from a wild elephant (Sukumar, 2004).

Management of the human-elephant conflict has become a topic of national, regional and international significance (Røskaft, Larsen, Mojaphoko, Sarker \& Jackson, 2014; Sarker, 2010; Skarpe, du Toit \& Moe, 2014). The high intensity of the conflict level between humans and elephants in Bangladesh has interrupted the smooth and long co-existence. People who live close to elephant habitats are now regarding them as an agricultural pest, an invader that damage property, and as a life-threatening animal (Sarker \& Røskaft, 2011). Therefore, there is a need to formulate preventive strategies in order to protect the vulnerable human population from wild elephant attacks and hence to save many valuable human as well as elephant lives. Thus, the aim of this study was to investigate the proportion of encounters intensity and consequences of elephant attacks on humans - in Bangladesh - as well as to describe the circumstances when those incidents commonly occur.

\section{Materials and Methods}

\subsection{Study Areas}

The study was performed in the south-eastern and northern regions of Bangladesh where the conflict between humans and wild elephants are common. The south-eastern region of Bangladesh consists of 11 of the 34 protected areas in the country and is managed by the Chittagong and Rangamati Forest Circle. This study was mainly confined to the regions near the Rangamati Forest Reserve (RFR), Banshkhali Forest Reserve (BFR), Chaunti Wildlife Sanctuary (CWS) and Teknaf Wildlife Sanctuary (TWS) based on their higher level of conflict vulnerability compared to other sites in the south-eastern region (Figure 1). The south-eastern region is associated with the Arkan forest area of Myanmar via a cross border corridor near the north bank of the Naf 
River between Teknaf, Bangladesh and Arkan province, Myanmar. Several corridors of elephants are networked over the entire south-eastern region.

The northern region only consists of the Sherpur forest reserve (SFR) (Figure 1), which includes Madhutila Eco-park. This area embraces a cross border corridor between Korigram, Mymensigh and the Sylhet forest regions of Bangladesh and West Bengal and Assam forest in India (Choudhury, 2007). Trans-border migratory wild elephants frequently visit the cross border corridor during movements from the Maghalaya forest region of Assam, India, to the Nalitabari and Zinaighati forest regions of Bangladesh.

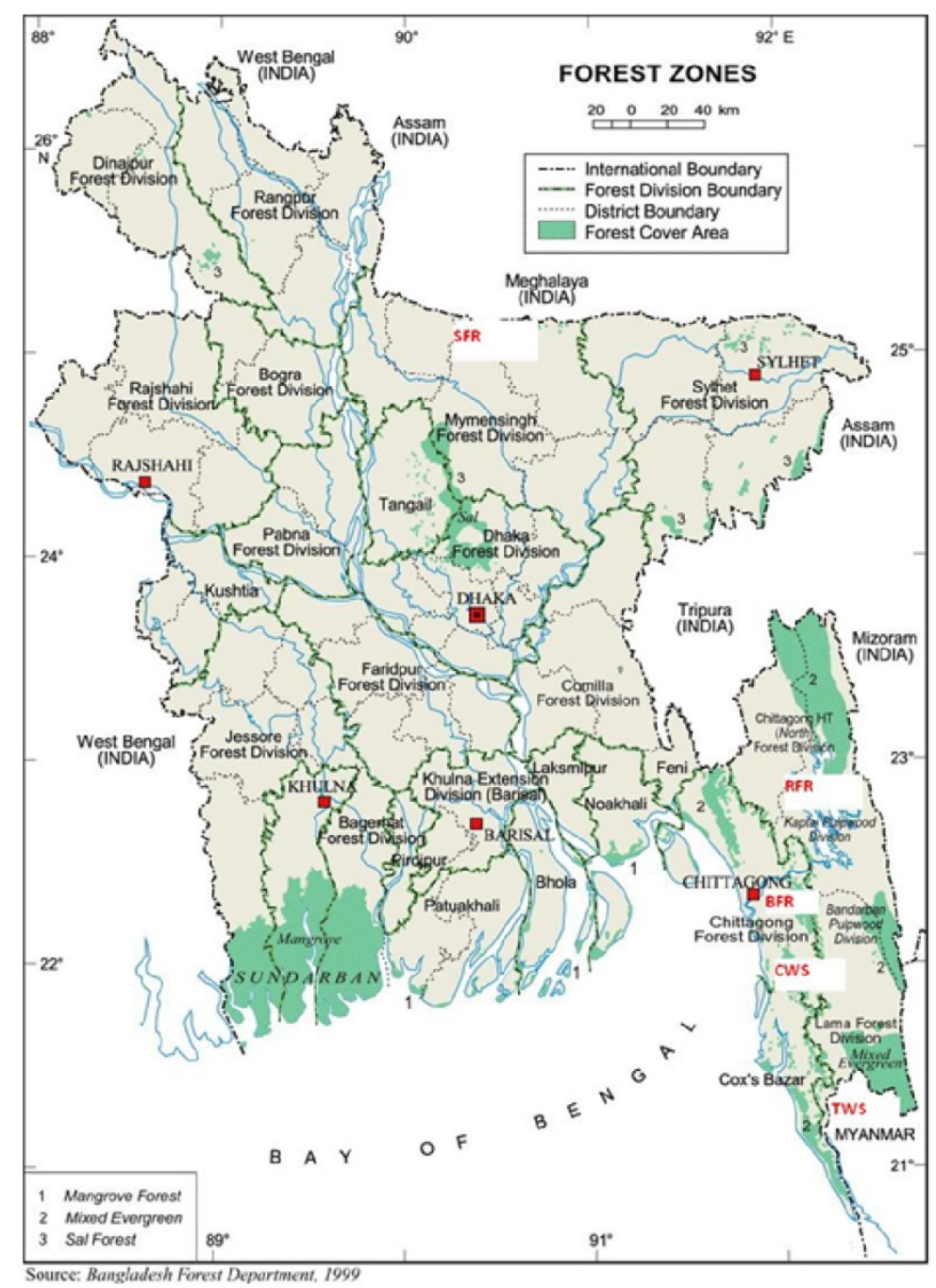

Figure 1. Location of study sites $(\mathrm{SFR}=$ Sherpur forest reserve, $\mathrm{RFR}=$ Rangamati Forest Reserve, $\mathrm{BFR}=$ Banshkhali Forest Reserve, CWS = Chaunti Wildlife Sanctuary and TWS = Teknaf Wildlife Sanctuary)

\subsection{Data Collection and Analyses}

Prior to the fieldwork, secondary resources, including published and unpublished research studies, conflict-related forest departmental documents and daily local and national newspapers, were studied to obtain the number and type of identified cases. We collected data on encounters of wild elephants, which caused either human death or injury during the period 1989-2012 by contacting Bangladesh Forest Department and requesting copies of investigation reports and other such information on elephant attacks. Injured victims were interviewed directly. In case of death of the victim, information was collected either by interviewing family or witnesses to the incident. Information on the victim's sex (male, female), age (young below 30 years, old above 30 years), occupation (work at home or outside the home), financial status (poor income below Tk 5000 per month, solve 
income above 5000 Tk per month); time of the day (night between $6 \mathrm{pm}$ and $6 \mathrm{am}$; day between $6 \mathrm{am}$ and $6 \mathrm{pm}$ ), season (dry October to May, wet June to September), year (1989-2000, 2001-2012), place of casualty (inside a protected forest, outside s protected forest in human dominated areas), elephant group size (single bulls, family groups) and activity of the victim during the attack by the wild elephant. Characteristics of elephant attacks were collected by using a semi-structured questionnaire. We applied a cross-examination process through checking records available in local police stations as well as in District Commissioner Offices to ensure data reliability. In case of a victim's death, we also checked the post-mortem report from the local hospital. Sometimes, the victim's family had left their settlement after an incident. In such a case, interviews were obtained from the victim's close relatives. A total of 224 recorded incidents of encounters between humans and wild elephants which resulted in deaths or injuries were recorded.

For simplicity, if at least one person died due to encountering wild elephant, we considered it as a death incidence, or if at least one person was injured it was considered as an injury incidence. Unless the attack was witnessed or confirmed by the local police they were not included in our data. The collected primary raw data were sorted on the basis of importance and usability for the purpose of easy, meaningful and high quality quantitative analyses.

\subsection{Statistical Analyses}

Most tests were performed using simple chi-square tests. A binary logistic regression analysis was performed to examine variations in human deaths or injuries as a dependent variable, and by using a set of independent variables such as sex, age group, financial status of victims, occupation status, household size, time of the day, season, year, place, study region, elephant group, body parts used as weapons by wild elephants (i.e., such as used the trunk, the legs, the tusk, or both trunk and legs). After coding and digitalisation the collected data, data analyses were performed by using SPSS version 20.0 (SPSS, Chicago, USA). The level of significance was set at P $=0.05$.

\section{Results}

\subsection{Socioeconomic Characteristics of Victims}

The proportion of the 224 encounters between humans and wild elephants which resulted in human deaths over the study period, was $76.8 \%(\mathrm{n}=172)$, while $23.2 \%(\mathrm{n}=52)$ caused human injuries. More males than females were attacked by elephants (Table 1). Furthermore, the proportion of incidents causing human deaths was statistically significantly higher in males than in females (Table 1). More encounters were registered in the older than the younger age group. The proportion of encounters that caused deaths or injuries was statistically significant different between two age groups (Table 1). Older people were more frequently killed than younger people. Finally, although more poor people and people working outside home were victims of elephant attacks, there were no significant differences in frequencies of deaths or injuries in relation to household size, occupation level or financial status of victims (Table 1).

\subsection{Study Periods}

A significant increase in frequency of encounters between humans and wild elephants was observed between the two periods $1989-2000$ to $2001-2012$ (Table 1). The majority of incidents between humans and wild elephants were recorded during 2001 to 2012. A significant higher frequency of deaths with more than $80.0 \%$ of the incidents causing human deaths occurred during this last period (Table 1).

\subsection{Period of the Day and Season}

The proportion of encounters resulting in deaths and injuries varied significantly between the two day periods (day or night) but insignificant between the two different seasons (Table 1). More attacks occurred during night with a much higher frequency of deaths compared to daylight period (Table 1). Although the dry season was much longer than the wet season, relatively more attacks occurred during the dry season.

\subsection{Place (Inside or Outside the Forest)}

Although the number of attacks did not differ inside or outside the protected forests, the proportion of deaths or injuries varied statistically significantly in relation to whether it occurred inside or outside the protected forests (Table 1). Most of the encounters, which caused human deaths, were reported inside the forest, while human injuries were considerably higher outside the forests (Table 1).

\subsection{Study Sites}

The highest proportion of encounters between humans and wild elephants was recorded in RFR ( $\mathrm{n}=91,40.6 \%)$, while the lowest was recorded in CWS $(n=23,10.3 \%)$. The number of encounters in the other study sites were; TWS $(\mathrm{N}=43,19.2 \%)$, BFR $(\mathrm{n}=42,18.8 \%)$ and SFR $(\mathrm{n}=25,11.2 \%)$. The proportion of encounters causing 
human deaths or injuries varied statistically significantly between the four study sites $\left(\chi^{2}=10.72, \mathrm{df}=4, \mathrm{P}=\right.$ 0.030). Although most incidents occurred in the south-eastern region the frequencies of injuries and deaths were insignificant between two regions (Table 1).

Table 1. Numbers of encounters between humans and wild elephants that resulted in human deaths or injuries in relation to socio-economic status, year and period of the day of incidents and place of casualty across the study sites and $\chi^{2}$ tests of independence between victims' status in the form of human deaths or injuries

\begin{tabular}{|c|c|c|c|c|c|c|c|c|}
\hline \multicolumn{3}{|c|}{ Variables } & \multicolumn{2}{|c|}{ Victim's status } & $\begin{array}{l}\text { Total } \\
(n=224)\end{array}$ & \multicolumn{3}{|c|}{ Statistics } \\
\hline \multirow{10}{*}{ 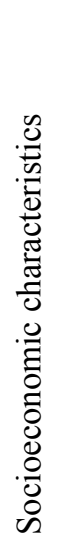 } & \multirow[t]{2}{*}{ Gender } & Male & $\begin{array}{l}\begin{array}{l}\text { Death } \\
(\mathrm{n}=172)\end{array} \\
139\end{array}$ & $\begin{array}{l}\begin{array}{l}\text { Injury } \\
(\mathrm{n}=52)\end{array} \\
23\end{array}$ & 162 & $\frac{\chi^{2}}{26.7}$ & $\frac{\mathrm{df}}{1}$ & 0.001 \\
\hline & & Female & 33 & 29 & 62 & & & \\
\hline & \multirow[t]{2}{*}{ Age group } & Young (0 to 30 years) & 44 & 22 & 66 & 5.37 & 1 & 0.020 \\
\hline & & Old (> 30 years $)$ & 128 & 30 & 158 & & & \\
\hline & \multirow[t]{2}{*}{ Financial status } & Poor $(<T k 5000)$ & 137 & 38 & 175 & 1.01 & 1 & 0.315 \\
\hline & & Solvent (>Tk 5000) & 35 & 14 & 49 & & & \\
\hline & \multirow[t]{2}{*}{ Household size } & Small HHs (up to 4 members) & 79 & 21 & 100 & 0.49 & 1 & 0.481 \\
\hline & & Large HHs (> 4 members) & 93 & 31 & 124 & & & \\
\hline & \multirow{2}{*}{$\begin{array}{l}\text { Occupation } \\
\text { status }\end{array}$} & Work outside home & 114 & 30 & 144 & 1.28 & 1 & 0.257 \\
\hline & & Work at home & 58 & 22 & 80 & & & \\
\hline \multirow{8}{*}{ 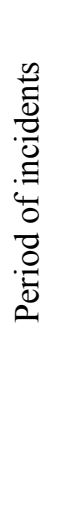 } & \multirow[t]{2}{*}{ Study periods } & 1989 to 2000 & 31 & 17 & 48 & 5.10 & 1 & 0.024 \\
\hline & & 2001 to 2012 & 141 & 35 & 176 & & & \\
\hline & \multirow[t]{2}{*}{ Time of the day } & Daylight (6 am to $6 \mathrm{pm})$ & 60 & 34 & 94 & 15.3 & 1 & 0.001 \\
\hline & & $\operatorname{Night}(6 \mathrm{pm}$ to $6 \mathrm{am})$ & 112 & 18 & 130 & & & \\
\hline & \multirow[t]{2}{*}{ Seasons } & Wet (June to September) & 32 & 12 & 44 & 0.51 & 1 & 0.477 \\
\hline & & Dry (October to May) & 140 & 40 & 180 & & & \\
\hline & \multirow[t]{2}{*}{ Forest reserve } & $\begin{array}{l}\text { Inside the reserve } \\
\text { (within the reserve boundary) }\end{array}$ & 98 & 10 & 108 & 22.8 & 1 & 0.001 \\
\hline & & Outside the reserve & 74 & 42 & 116 & & & \\
\hline \multirow{3}{*}{ 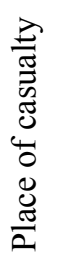 } & \multirow{3}{*}{ Region } & $\begin{array}{l}\text { (up to } 1 \mathrm{~km} \text { away from the reserve } \\
\text { boundary) }\end{array}$ & & & & & & \\
\hline & & Northern (i.e., SRF) & 16 & 9 & 25 & 2.58 & 1 & 0.108 \\
\hline & & $\begin{array}{l}\text { Southeastern } \\
\text { (i.e., RFR, CWS, BFR, TWS) }\end{array}$ & 156 & 43 & 199 & & & \\
\hline
\end{tabular}

\subsection{Elephant Social Groups}

Single elephants were bulls $(\mathrm{n}=108,48.2 \%)$, while groups normally counted family herds $(\mathrm{n}=116,51.8 \%)$. There was no statistically significant difference in the encounters of single bulls or group attacks in relation to the victim's gender $\left(\chi^{2}=0.001, \mathrm{df}=1, \mathrm{P}=0.974\right)$, age group $\left(\chi^{2}=0.68, \mathrm{df}=1, \mathrm{P}=0.088\right)$, financial status $\left(\chi^{2}=\right.$ $3.32, \mathrm{df}=1, \mathrm{P}=0.190)$, or between the two study periods $\left(\chi^{2}=0.87, \mathrm{df}=1, \mathrm{P}=0.352\right)$. These encounters were not significantly different with time of day $\left(\chi^{2}=0.39, \mathrm{df}=1, \mathrm{P}=0.529\right)$, different seasons $\left(\chi^{2}=2.39, \mathrm{df}=1, \mathrm{P}=\right.$ 0.496). Consistent with these findings, there was no statistically significant variation in the elephant social group encountering attack rate, independent of whether the encounter occurred inside or outside of the protected forests $\left(\chi^{2}=0.05, \mathrm{df}=1, \mathrm{P}=0.826\right)$. 
The incidents of single and group encountering attacks varied statistically significant between the two regions $\left(\chi^{2}\right.$ $=8.97, \mathrm{df}=1, \mathrm{P}=0.003)$; family groups $(80.0 \%)$ were mostly responsible in the north, while single bulls $(51.8 \%)$ were more responsible in the southeast.

Table 2. Results of logistic regression analyses to examine the effects of 12 independent variables (see text for details) on variations in human death or injury as a dependent variable

\begin{tabular}{lllllll}
\hline Independent variables & $\mathrm{B}$ & $\mathrm{SE}$ & Wald & $\mathrm{df}$ & $\mathrm{P}$ & Odds ratio $^{1}$ \\
\hline Place (inside/outside) & 2.577 & 0.528 & 23.865 & 1 & 0.0001 & 13.162 \\
Time of the day & -1.726 & 0.444 & 15.080 & 1 & 0.0001 & 0.178 \\
Gender & 1.871 & 0.507 & 13.601 & 1 & 0.0001 & 6.496 \\
Region & -1.224 & 0.638 & 3.675 & 1 & 0.055 & 0.294 \\
Status of attacked elephant & 0.736 & 0.429 & 2.946 & 1 & 0.086 & 2.087 \\
Age & -0.533 & 0.453 & 1.386 & 1 & 0.239 & 0.587 \\
Occupation & -0.587 & 0.517 & 1.290 & 1 & 0.256 & 0.556 \\
Body parts as weapon & 0.668 & 0.757 & 0.780 & 1 & 0.377 & 1.950 \\
Season & 0.451 & 0.520 & 0.755 & 1 & 0.385 & 1.571 \\
Monthly income (Tk) & 0.355 & 0.472 & 0.564 & 1 & 0.453 & 1.426 \\
Household size & 0.267 & 0.429 & 0.387 & 1 & 0.534 & 1.306 \\
Year of incidents & -0.026 & 0.523 & 0.002 & 1 & 0.961 & 0.975 \\
\hline
\end{tabular}

${ }^{1} \mathrm{~A}$ measure of association between each independent and dependant variables. When $\mathrm{B}$ is negative, the odds ratio must be inverted (1/odds ratio) to indicate the relevant odds. Cox \& Snell $r^{2}=0.297$, Nagelkerke $r^{2}=0.449$.

\subsection{Body Parts Used as Weapons by Wild Elephants}

Elephants usually used their trunk $(n=92,41.1 \%)$, leg $(n=15,6.7 \%)$, tusk $(n=19,8.5 \%)$, or both their trunk and legs $(n=98,43.8 \%)$ as a weapon when encountering a human being $\left(\chi^{2}=34.35\right.$, df $\left.=3, P=0.0001\right)$. If an elephant used the trunk and leg combined, then the proportion of encounters causing human deaths $(n=92$, 93.9\%) dramatically increased compared to other types of weapons, such as by the trunk only $(n=56,60.9 \%)$, by the legs only $(n=8,53.3 \%)$, or by the tusk only $(n=16,84.2 \%)$. However, there was no difference between the single bull or family groups in the use of these different body parts when encountering humans $\left(\chi^{2}=3.09\right.$, df $=3, \mathrm{P}=0.378)$.

A binary logistic regression analysis was performed to examine variations in human deaths or injuries as a dependent variable using twelve independent variables [i.e., study sites, year of incidents, season, time of the day, inside/outside forest, group size of wild elephants, weapon used by wild elephants and socio-demographic characteristics of victims (such as monthly income, age, gender, occupation and family size)]. The analysis shows that place of casualty (i.e., inside or outside forest reserve), time of the day (i.e.,daylight and night), gender (i.e., male and female) and regions (i.e., northern and south-eastern) were significant in explaining the variation in encounters which resulted in human deaths or injuries (Table 2).

\section{Discussion}

\subsection{Socio-Economic Features of Victims}

As previously discussed by Bandara and Tisdell (2003), of a total number of 536 causalities due to elephant's encounter attacks between 1992 and 2001 in Sri Lanka, 75.0\% were males, 13.0\% females and 12.0\% infants. In our study, the binary logistic regression analysis also revealed that the highest proportion of encounters causing human deaths was reported in males. Males are more involved in forest-related activities as well as farming near forest reserves, whereas females are more involved in non-forest activities (Aziz, 2002; Røskaft, Hagen, Hagen \& Moksnes, 2004). During male-dominated activities, men are encountered by elephants in most forest areas, while women are attacked in their residences during the night (see also, (Røskaft, Bjerke, Kaltenborn, Linnell \& Andersen, 2003; Treves \& Naugthon-Treves, 1999)). When agricultural crops are not available in the field, wild elephant herds may attack in the residential areas where grains are stored. Under such circumstances, most males 
escaped easily from their homes due to having better physical fitness, while females are busy to protect household assets as well as their children from the encountering of wild elephants.

In our study, we found that the proportion of encounter rate of wild elephants which resulted in human deaths was higher among older people, most likely due to many factors, such as lack of physical fitness of older people to escape from the wild elephant, or it may be that this is the most common age group (i.e., adults) that collects natural resources in the forests (IUCN, 2004b). When old people are entrapped by an attacking elephant, they are unable to escape from this dangerous place. Furthermore, the old age group is the most frequent group engaged in forest-related activities. For this reason, people from this group are more easily affected by elephant's encounters.

\subsection{Study Period, Periods of the Day, Season and Place (Inside or Outside of the Forest) of Elephant Encounters}

There was significant increase in attacks by elephants during the study period, probably due to many factors, the most important being lack of space for elephants. The number of people encountered by wild elephants gradually increased over the last 24 years (1989 to 2012), which was partly due to the population increase in Bangladesh as well as the dramatic reduction in elephant habitats due to several anthropogenic factors. The encountering rates between wild elephants and human increased from 1989-2000 to 2001-2012 as in our study more than two-third of all incidents were recorded during 2001 to 2012. The first human death was reported in the Rangamati region in 1989. During the years before the turn of the century, the intensity of encountering wild elephants was negligible due to less migration of local people towards forested areas. However, after the year 2000, a huge number of humans have been migrating to the forested zones due to the employment crisis and poverty. They have encroached the elephant's habitats, blockaded corridors and transformed forest land into agricultural land at extreme levels and continuing the overexploitation of forest resources for their subsistence or livelihood purposes. Moreover, weak forest management systems are considered to be the key causes for the deterioration or degradation of elephants' habitats across study areas, which forces wild elephants come to close contact with humans and ultimately increases the intensity of human-elephant conflict over recent years (Khan, Rashid \& Khan, 1983; Sarker, 2010; Sarker \& Røskaft, 2011).Thus, encounters of wild elephants on human are increasing in and around the protected areas in recent times in both the northern and south-eastern part of Bangladesh.

Human encounters by wild elephants also varied during the daytime. As previously discussed by Sukumar (2004), the highest encounters of wild elephants occurred during dark/dusk during the harvesting period, which was consistent with our findings. A few attacks by single bulls might also occur inside the forest during noon, afternoon and early evening when victims are alone inside the forest and are busy collecting forest resources (Feeroz, Aziz, Islam \& Islam, 2004). However, at noon and in the afternoon, elephants are mostly resting in a quiet shady place inside the forest or near a body of water. During the evening, the elephants come out from these resting areas, while humans are still active inside the forest and in the cropping fields. During night, when most fatalities occurred, wild elephants are coming close to human settlements where humans are disturbed. Thus they are attacked when they try defending their homes and properties. During the cropping season, wild elephants frequently raid forests close to residential areas. When moving between such areas, they frequently use roads during, resulting in an increased rate of attacks in areas outside of, but close to the forests. The encounter rates increased during the peak cropping season in areas outside the forests due to the availability of a ripen paddy, which attracts wild elephants. Wild elephants prefer the paddy because it provides a nutritious source for grazing. The availability of agricultural crops is lower in the agricultural fields during the spring and summer, but farmers home garden are rich in horticultural crops during that time. Wild elephants encounter home gardens and more causalities occurred in the settlements during the non-pick seasons (Sarker \& Røskaft, 2010; Sukumar, 2006). Elephants enter human settlement zones only after dark, and elephants usually move close to the forestvillage boundary in the early evening during the cropping seasons (Sukumar, 1989). Settlement zones including crop fields and home gardens are not however, generally guarded on a 24-hour basis and are tended only during the daylight hours. Most of the encounters, therefore, take place at night when the crop fields or homestead gardens are unattended. Farmers construct thatched houses (huts) during the harvest season (especially the rice harvest) to guard their fields and home gardens at night. Such guarding activities are always carried out in groups (Sarker \& Røskaft, 2010). Therefore, in the early evening, large guard groups make it possible to guard against crop raiding and drive elephants from the field. However, farmers are unable to maintain large groups throughout the late evening due to lack of sleep. Moreover, they are financially unable to hire night guards. On the other hand, illicit fellers entered into the forest at night to extract timber and other resources for their livelihood and encountered wild elephants in there. Under such condition, they failed to trace out the presence of wild elephants and in most of the cases they failed to escape from the elephant's attacks resulting in human deaths. The logistic regression analysis also shows similar results in our study. Thus, the highest proportion of 
elephant's attacks occurred during night and resulted in a much higher frequency of deaths compared to daylight period the inside the forest.

\subsection{Study Sites (Regions)}

Currently, wild elephants are only found in south-eastern and northern hilly forest areas (Islam, Mohsanin, Chowdhury, Choudhury, Aziz, et al., 2012). In the northern parts of Bangladesh, elephants are only found in and around the Sherpur forest reserve (SFR), whereas in the south-eastern part, they are found in several locations, more specifically in and around TWS, CWS, BFR and RFR under Chittagong and Rangamati Forest Circles. The south-eastern region, particularly the Chittagong, Cox's Bazar and Rangamati districts in Chittagong Hill Tracts (CHTs), was the region with the highest number of wild elephant's encounters on humans. This region is also a refuge of diversified indigenous and non-indigenous people. A large number of illiterate people have settled down in this region from other parts of Bangladesh because the region is rich in forest-based natural resources (Sarker \& Røskaft, 2011).

We found that the encounter rates of wild elephants were higher in RFR while lowest in CWS. The RFR has large areas with elephant habitats and the availability of both local and trans-border migratory wild elephants from India and Myanmar. Unsustainable tribal and non-tribal human activities inside the forests are thus responsible for more encounters of wild elephants in the south-eastern region of Bangladesh (IUCN, 2004a). The findings of the study revealed that the proportion of encounter which resulted in human deaths or injuries was considerably higher in the RFR than other study sites. The reason is that wild elephants in this region have gradually been confined to 'pocketed herds' in small patches of forest due to construction of the Kaptai dam and highway, which has caused isolation of wild elephants from their mainstream population. Furthermore, most farmers inhibited around RFR are involved in jhum (shifting cultivation), which makes the wild elephants almost a seasonal aggressive invader into farm fields and densely dwelling places located in the RFR and resulting in many human fatalities during these seasons. Moreover, small size of reserves increases the frequent contact of humans and wild elephants, thus ultimately increases encountering rates between wild elephants and human which causes more human deaths or injuries. Probably, due to this reason, we found that the higher rate of encounters of wild elephants causing human deaths or injuries was higher in RFR. On the other hand, the CWS has high human densities with settlements that surround the forest areas. Thus, only a low number of elephant herds can potentially intrude into these due to the blockade of the corridor and enormous human interfering activities (Sarker \& Røskaft, 2011). The high rate of human causalities might hinder the elephant conservation strategy due to a dramatic increase in the negative attitudes of people (Sarker \& Røskaft, 2010; Sarker \& Røskaft, 2011).

\subsection{Elephant Social Groups}

No significant difference between single males or family groups encountering attacks was found with respect, but single or group encountering attacks varied according to the time of day. During the daylight, the forest walking people are mostly affected by single males, whereas at night, the number of attacks by family groups increased. Encounters were amplified during the peak crop season, but the off-season group encountering attacks increased compared to single encountering attacks, which might be due to differences in the behaviour between single bulls and family groups.

\subsection{Body Parts Used as Weapons by Wild Elephants}

The fatality rate ( $80.3 \%$ human death rate) might be considered as a consequence of the elephant's encountering attack behaviour, while the intensity of fatalities was dependent on the style of elephant encountering attack. During an encountering attack, the wild elephant either used the leg, trunk, or tusk as a weapon or a combination of the trunk and leg with different results. We would expect that wild bull elephants most frequently practiced offensive attacks (leg and trunk) due to their changing hormone levels, whereas herds practice more defensive attacks (a single weapon) as a less offensive strategy (IUCN, 2004b). However, when herds are carrying infants in the group or when they are passing through during the breeding period, they showed a more aggressive behaviour and normally used an offensive encountering attack style which is trunk and leg (Sukumar, 1991). During an aggressive offensive encountering attack, both bulls and herds used legs and trunks combined at similar frequencies and consequently increased the fatality rate. Therefore, family groups were mostly responsible for human deaths in the north, while single bulls were more responsible in the southeast. However, when elephants are less aggressive, they mostly used the leg or sometimes only the trunk to avoid a conflict. During frontal encountering attacks, they used the tusk, trunk or even the leg and trunk combined during an encounter and attack raid. As a consequence of such encounters, fewer fatalities in terms of deaths were observed, while a medium number of fatalities occurred after using the trunk or tusk while a high fatality rate occurred after using the leg and trunk combined. 


\section{Concluding Remarks}

The findings of this study indicate that the rate of encountering wild elephants has gradually increased into recent times, also being more serious because they more frequently are causing human deaths. All types of forest-related illegal activities, such as settlement in forests, illegal forest entrances and forest resource exploitation, weaken the forest management system and are primary causes for the high rate of human-elephant conflict. Human and elephant conflict has introduced a new dimension of conflict between the local people and forest authorities. However, most causality occurs during illegal forest-related activities and in illegal settlements. Indeed, the new wildlife act allows compensation for people injured or killed even during illegal activities and in illegal settlements. However, this new dimension of conflict is limited by the lack of mutual cooperation between local people and forest authorities. Wild elephants play a significant role in protecting natural forests, which offer different types of ecosystem services that are essential for human life, the conservation of elephants should be a human moral, ethical and mandatory task to ensure the survivability of this threatened species in the wild. If it is possible to reduce the human and elephant conflict level by terminating the revenge killing of elephants, then the forest will be protected and human life would be safer. The conflict mitigation approaches and welfare activities, including incentive programs, awareness programs and training programs from the forest department, could help to reduce the conflict between humans and wildlife. Unless active conservation measures are taken immediately, the elephant will most probably go extinct in Bangladesh in a few years to come.

\section{Acknowledgements}

AH was supported by a grant through the Norwegian University of Science and Technology (Quota).We are very grateful to our five research gatekeepers in the five study areas in Bangladesh for their assistance and support during our field work. We are also grateful to the staff and officers of the Bangladesh Forest Division for their assistance and cooperation.

\section{References}

Aziz, M. A. (2002). Ecology of Asian elephants, Elephas maximus and its interaction with man in the Chittagong Hill Tracts. M. Sc. thesis, Department of Zoology, Jahanghirnagar University.

Bandara, R., \& Tisdell, C. (2002). Asian elephants as agricultural pests: damages, economics of control and compensation in Sri Lanka. Natural Resources Journal, 42, 491-519.

Bandara, R., \& Tisdell, C. (2003). Comparison of rural and urban attitudes to the conservation of Asian elephants in Sri Lanka: empirical evidence. Biological Conservation, 110, 327-342.

Choudhury, A. (2007). Impact of border fence along India-Bangladesh border on elephant movement. Gajah, 26, 27-30.

Feeroz, M. M., Aziz, M. A., Islam, M. T., \& Islam, M. A. (2004). Human-elephant conflict in southeastern hilly areas of Bangladesh. In J. Jayewardene (Ed.), Endangered elephants: past, present and future (pp. 98-102). Colombo, Sri Lanka: Biodiversity \& Elephant Conservation Trust.

Hossain, J. (2008). Review of CBD programme work in Bangladesh. Forest People's Programme.

Islam, M. A., Mohsanin, S., Chowdhury, G. W., Choudhury, S. U., Aziz, M. A., Uddin, M., \& Azam, I. (2012). Current status of Asian elephant in Bangladesh. Gajah, 35, 21-24.

IUCN. (2004a). Assessment of elephant habitat and local capacity and awareness enhancement programme at Chunati Wildlife Sanctuary. The World Conservation Union, Bangladesh Country Office.

IUCN. (2004b). Human-elephant conflicts in Bangladesh and assessment of financial losses. The World Conservation Union, Bangladesh Country Office.

Jones, S., \& Carswell, G. (2004). The earthscan reader in environmental, development and livelihoods. Trowbridge, UK: Cromwell press.

Khan, M. A., .R., Rashid, S. M. A., \& Khan, A. Z. (1983). Development of a management plan for the elephants of Cox's Bazar Forest Division (South), Bangladesh. Department of Zoology, University of Dhaka.

New-Nation. (2015). One person killed in elephant attack in Netrokoma. Retrieved 17 December, 2014, from http://thedailynewnation.com/news/37696/one-killed-in-elephant-attack-in-netrakona.html

PA. (2014). Two humans killed in Chittagong elephant attck. Retrieved 17 December, 2014, from http://en.prothom-alo.com/bangladesh/news/57169/2-killed-in-Ctg-elephant-attack 
Ramakrishnan, B., \& Ramkumar, K. (2007). Land acquisition perspectives of vital elephant corridors in the Coimbatore and Sathyamangalam Forest Divisions, Tamil Nadu, South India. Wildlife Trust of India.

Reuters. (2001). 15 people killed in an elephant attck. Retrieved from http://factsanddetails.com/asian/cat68/ sub431/item2466.html

Reuters. (2002). Elephants trample 3 humans. Retrieved from http://igorilla.com/gorilla/animal/2002/elephants_ trample_3.html

Robbins, P. (2012). Political ecology: A critical introduction (2nd ed.). Wiley-Blackwell.

Røskaft, E., Bjerke, T., Kaltenborn, B. P., Linnell, J. D. C., \& Andersen, R. (2003). Patterns of self-reported fear towards large carnivores among the Norwegian public. Evolution and Human Behavior, 24(3), 184-198. http://dx.doi.org/10.1016/S1090-5138(03)00011-4

Røskaft, E., Hagen, M. L., Hagen, T. L., \& Moksnes, A. (2004). Patterns of outdoor recreation activities among Norwegians: an evolutionary approach. Annales Zoologici Fennici, 41(5), 609-618.

Røskaft, E., Larsen, T., Mojaphoko, R., Sarker, A. H. M. R., \& Jackson, C. (2014). Human dimensions of elephant ecology. In C. Skarpe, J. Du Toit, \& S. Moe (Eds), Elephants and Savanna Woodland Ecosystems: A study from Chobe National Park, Botswana (pp. 271-288). Oxford: Wiley Blackwell.

Sarker, A. H. M. R. (2010). Human-wildlife conflict: A comparison between Asia and Africa with special reference to elephants. In E. Gereta, \& E. Røskaft (Eds.), Conservation of natural resources; some African $\&$ Asian examples (pp. 186-210). Trondheim: Tapir academic press.

Sarker, A. H. M. R., \& Røskaft, E. (2010). Human attitudes towards conservation of Asian elephants (Elephas maximus) in Bangladesh. International Journal of Biodiversity and Conservation, 2(10), 316-327.

Sarker, A. H. M. R., \& Røskaft, E. (2011). Human attitudes towards the conservation of protected areas: a case study from four protected areas in Bangladesh. Oryx, 45(3), 391-400. http://dx.doi.org/10.1017/S0030605310001067

Skarpe, C., du Toit, J. T., \& Moe, S. R., eds. (2014). Elephants and savanna woodland ecosystems, A study from Chobe National Park, Botswana. Volume 14. Cambridge: Wiley Blackwell.

Sukumar, R. (1989). The Asian elephant - ecology and management. Cambridge. UK: Cambridge University Press.

Sukumar, R. (1991). The management of large mammals in relation to male strategies and conflict with people. Biological Conservation, 55(1), 93-102. http://dx.doi.org/10.1016/0006-3207(91)90007-V

Sukumar, R. (2004). The living elephants: Evolutionary ecology, behavior and conservation. New York, USA: Oxford University Press.

Sukumar, R. (2006). A brief review of the status, distribution and biology of wild Asian elephants. Int Zoo Yearbook, 40, 1-8.

Treves, A., \& Naugthon-Treves, L. (1999). Risk and opportunity for humans coexisting with large Carnivores. Journal of Human Evolution, 36(3), 275-282. http://dx.doi.org/10.1006/jhev.1998.0268

\section{Copyrights}

Copyright for this article is retained by the author(s), with first publication rights granted to the journal.

This is an open-access article distributed under the terms and conditions of the Creative Commons Attribution license (http://creativecommons.org/licenses/by/3.0/). 